\title{
Organization of copper nanoclusters in Langmuir-Blodgett films
}

\author{
G HEMAKANTHI, ARUNA DHATHATHREYAN* and T RAMASAMI \\ Chemical Lab., Central Leather Research Institute, Chennai 600 020, India
}

MS received 26 December 2000; revised 24 September 2001

\begin{abstract}
Stable nanoclusters of $\mathrm{Cu}$ were synthesized using Langmuir-Blodgett films of octadecylsuccinic acid (ODSA) as template. The Langmuir-Blodgett films of ODSA formed from subphase containing copper ions were first subjected to sulphidation (S) using sodium sulphide and then hydrogenated $(\mathrm{H})$ using hydrogen gas. Diffuse reflectance UV-visible spectroscopy (DIR-UV-vis), X-ray photoelectron spectroscopy (XPS) and transmission electron microscopy (TEM) used to characterize these films indicated the formation of $\mathrm{Cu}(0)$ metallic clusters ranging in size from $3 \sim 10 \mathrm{~nm}$.
\end{abstract}

Keywords. Copper clusters; LB films; XPS.

\section{Introduction}

In recent years, considerable interest has arisen in the production of metallic nanoparticles and nanoparticulate films due to their unique optical (Preston and Moskovita 1993), electronic and magnetic properties (Haruta et al 1987). They also constitute a wide class of catalysts and because catalysis occurs on the surface there is a necessity to obtain monodisperse metallic particles. A number of methods have been employed for preparing metallic nanoparticles including controlled reduction in aqueous solutions (Haruta et al 1987; Jana and Biswas 2000), with and without surfactants (Kurihara et al 1983), synthesis in host matrix (Mancin et al 2000) including polymers (Joly et al 2000), porous inorganic networks ( $\mathrm{Tu}$ and Liu 2000), tubules (Burkett and Mann 1996), silica gels (Tanahasi and Mitsuyu 1995), porous membranes (Sharma and Borovik 2000), monolayers at air/water interface (Kotov et al 1993) and Langmuir-Blodgett films (LB films) (Fujihara and Possittsak 1986). A recent review on synthesis of nanosized particles in colloidal assemblies has dealt extensively on the parameters that play a role in the control of size, shape and polydispersity of these particles (Pileni 1997). In all these methods, electrodeposition (Penner 2000) and LB films (Tang et al 1997; Xiong et al 1998; Penner 2000) are two techniques that are frequently used to obtain $2 \mathrm{D}$ and $3 \mathrm{D}$ structures of the nanoparticles in ordered arrays. A number of articles have appeared wherein it has been demonstrated that metal clusters like those of silver and gold may be inserted chemically into LB films (Liu and Cai 2000). Multiparticulate metal films of silver clusters were prepared by Fendler and coworkers (Meldrum et al 1994) and also by Zhang and co-

*Author for correspondence workers (Zhang et al 1996). 'Ligand mobilized metal clusters' in different oxidation states were synthesized by us earlier by using LB films of amphiphilic schiff bases (Hemakanthi and Dhathathreyan 1999, 2001). Lisiecki and Pileni $(1993,1995)$ had earlier reported controlling of sizes of $\mathrm{Cu}(0)$ metallic clusters using different water contents in reverse micellar environment. Compared to use of micelles for preparation of metal clusters, LB films as templates have the advantage that the extraction of unreacted amphiphile does not pose a big problem. We report here the formation of $\mathrm{Cu}(0)$ metallic clusters by first forming copper complex of octadecylsuccinic acid (ODSA) at air/water interface, then carrying out sulphidation $(\mathrm{S})$ using $\mathrm{Na}_{2} \mathrm{~S}$ and hydrogenation $(\mathrm{H})$ using $\mathrm{H}_{2}$ on the LB films formed thereof. The metallic clusters thus obtained were characterized using diffuse reflectance UVvisible spectroscopy (DIR-UV-vis), X-ray photoelectron spectroscopy (XPS) and electron microscopy, which indicate that the sizes of these clusters range from 3$10 \mathrm{~nm}$.

\section{Experimental}

ODSA (>99.9\% purity) was obtained from Lancaster chemicals, UK and used without further purification. ODSA was dissolved in HPLC grade dichloromethane/ methanol mixture ( $1 \%$ methanol) to give millimolar solution and the solution was spread on water (deionized milliQ (millipore)), $\mathrm{pH}=5 \cdot 5$. The effective complexation of metal ions with ODSA were monitored as a function of $\mathrm{pH}$ and it was found that the stability of the complex was very high at $\mathrm{pH} 5 \cdot 5$. Hence this $\mathrm{pH}$ was chosen. $\mathrm{Na}_{2} \mathrm{~S}$ and all other reagents used in the study were of analar grade and obtained from Merck, India. Quartz $(30 \times 10$ $\times 1.5 \mathrm{~mm}$ ) for UV-visible spectra and cover glass slips 
$(10 \times 10 \times 1.25 \mathrm{~mm})$ for XPS measurements were cleaned thoroughly with chromic acid and sonicated in isopropyl alcohol and were used to transfer the monolayers using the LB film technique. The films were transferred at a constant surface pressure $(\pi)$ of $20 \mathrm{mN} / \mathrm{m}$ and the transfer ratios were nearly 0.9 . The transfer was Y-type. The addition of copper complex, its conversion to the metal sulphide and subsequent hydrogenation were carried out as follows (i) preparation of ODSA monolayers on copper containing subphase (concentration $0.5 \mathrm{mM}$ ) and LB film of the metal complex, (ii) sulphidation (S) of the LB film to give copper sulphide in the hydrophobic interlayers of the LB film by exposing the films from step (i) to (a) a reaction chamber containing $\mathrm{Na}_{2} \mathrm{~S}$ in isopropyl alcohol and (iii) exposing the films from step (ii) to $\mathrm{H}_{2}$ gas.

The formation of pure ODSA and the copper complex of ODSA were confirmed by measuring the $\pi-A$ isotherms using a computer controlled NIMA 611 trough attached to a thermostat. The LB film deposition of 20 layers for the UV-visible spectra were carried out on quartz substrates by vertical dipping.

The metal sulphide was obtained by exposing the copper complex to $\mathrm{Na}_{2} \mathrm{~S}$ for $20 \mathrm{~min}$ at room temperature. The formation of copper sulphide was monitored using the UV-visible spectra and compared with the pure metal complex. The same procedure was repeated with the films after hydrogenation also. The UV-visible spectra of LB films were recorded with a Shimadzu 160A spectrophotometer in the absorbance mode and the absorption onset $\left(\lambda_{\mathrm{m}}\right)$ of the copper sulphide and the reduced film

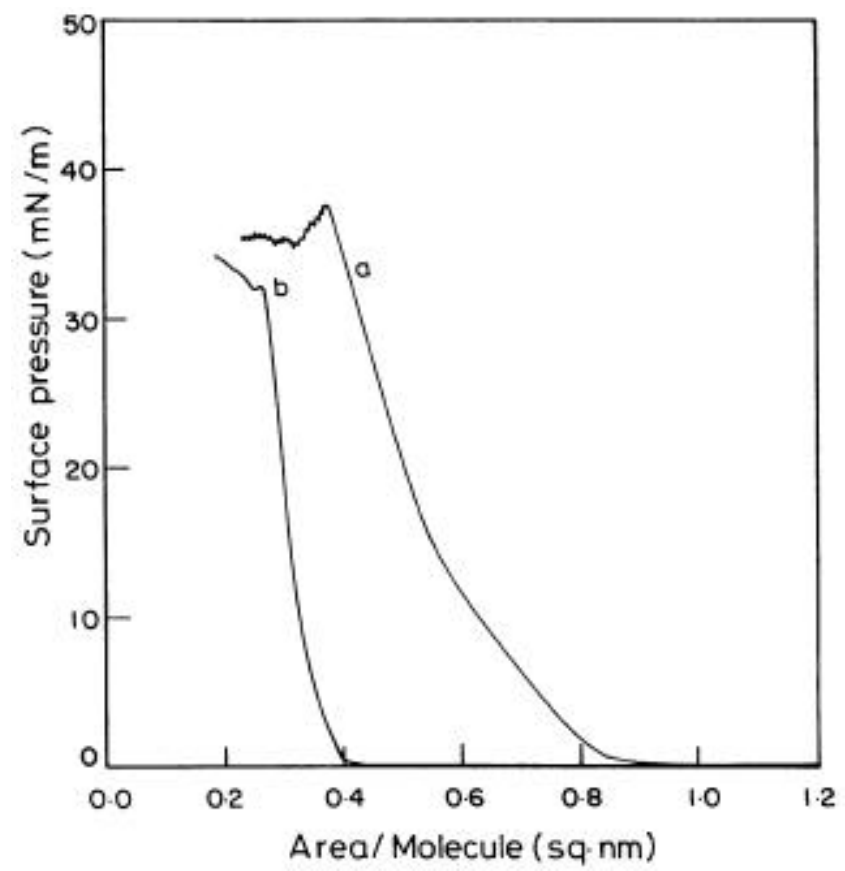

Figure 1. $\pi-A$ isotherms of curve a (ODSA) and curve $b$ (copper complex of ODSA at room temperature) (concentration $0.5 \mathrm{mM})$. was determined as the wavelength of the peak maximum in the doubly differentiated spectrum. Diffuse reflectance spectroscopy was measured using a Perkin Elmer (model Lambda 14) spectrophotometer fitted with a labsphere RSA-PE20 accessory and the signals measured using a normalized Kubelka-Munk function against wavelength.

The X-ray photoelectron spectra (XPS) of the glass supported films were recorded in an instrument, model MKII, VG Scientific, UK with a MgK $\alpha$ source $(1253.6 \mathrm{eV})$. Binding energies were calibrated with reference to $\mathrm{C} 1 s_{1 / 2}$ line of the aliphatic carbon $(285.0 \mathrm{eV})$. The presence of $\mathrm{S}_{2 p}, \mathrm{Cu} p_{1 / 2}$ were estimated by analysing the integrated peak area.

The transmission electron micrographs (TEM) were taken using a Philips-STEM equipment $(100 \mathrm{kV})$.

\section{Results and discussion}

The surface pressure-molecular area $(\pi-A)$ isotherms of ODSA on pure water and on copper containing subphase are shown in figure 1. Curve ' $a$ ' corresponding to the pure ODSA shows a close packed area of $0.40 \mathrm{~nm}^{2} /$ molecule at $\pi=20 \mathrm{mN} / \mathrm{m}$. The corresponding isotherm of ODSA on copper containing subphase (curve ' $b$ ') shows a contraction in molecular area to $\sim 0.30 \mathrm{~nm}^{2} /$ molecule

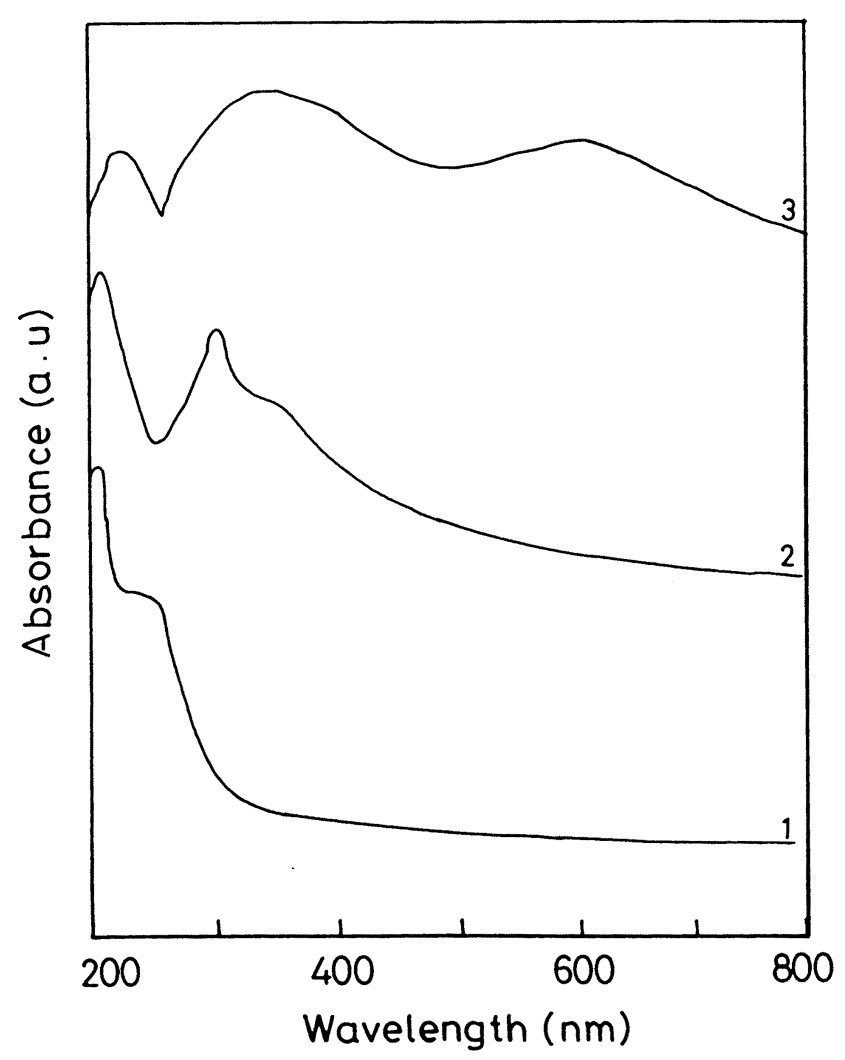

Figure 2. UV-visible spectra of LB film of ODSA (20 layers) (curve 1, copper complex; curve 2, copper complex after sulphidation; and curve 3 , after hydrogenation). 


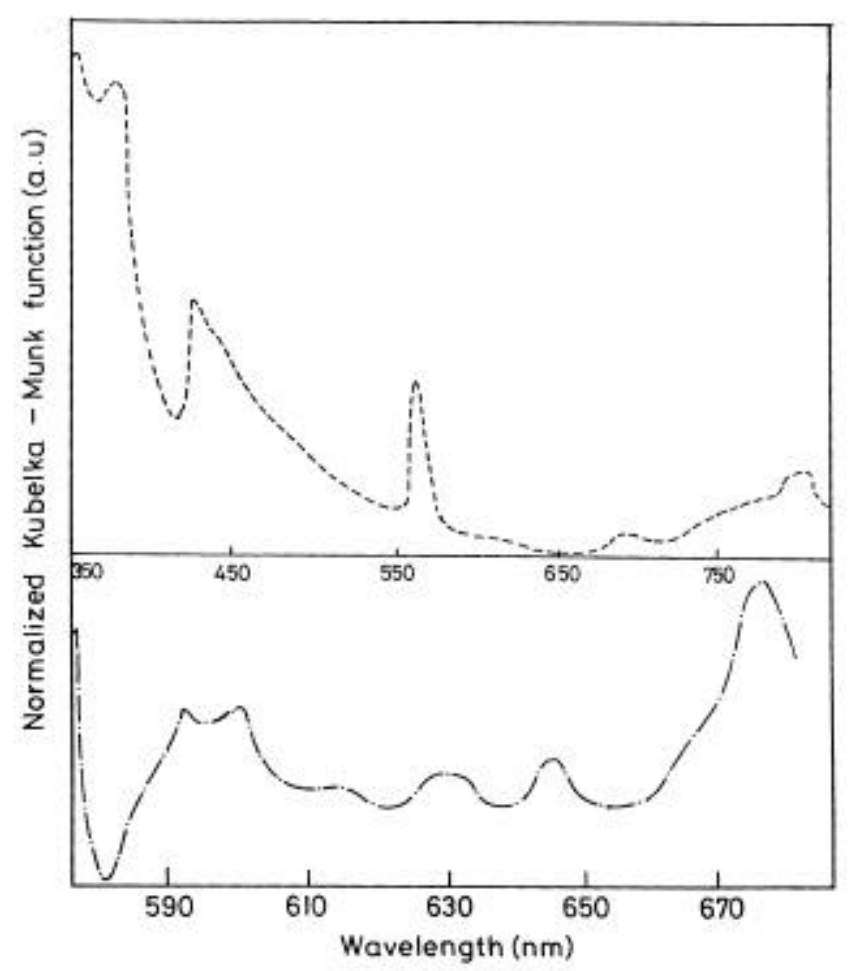

Figure 3. Diffuse reflectance spectra of copper complex of ODSA after hydrogenation (Top, 350-800 nm; bottom, 570$690 \mathrm{~nm})$.

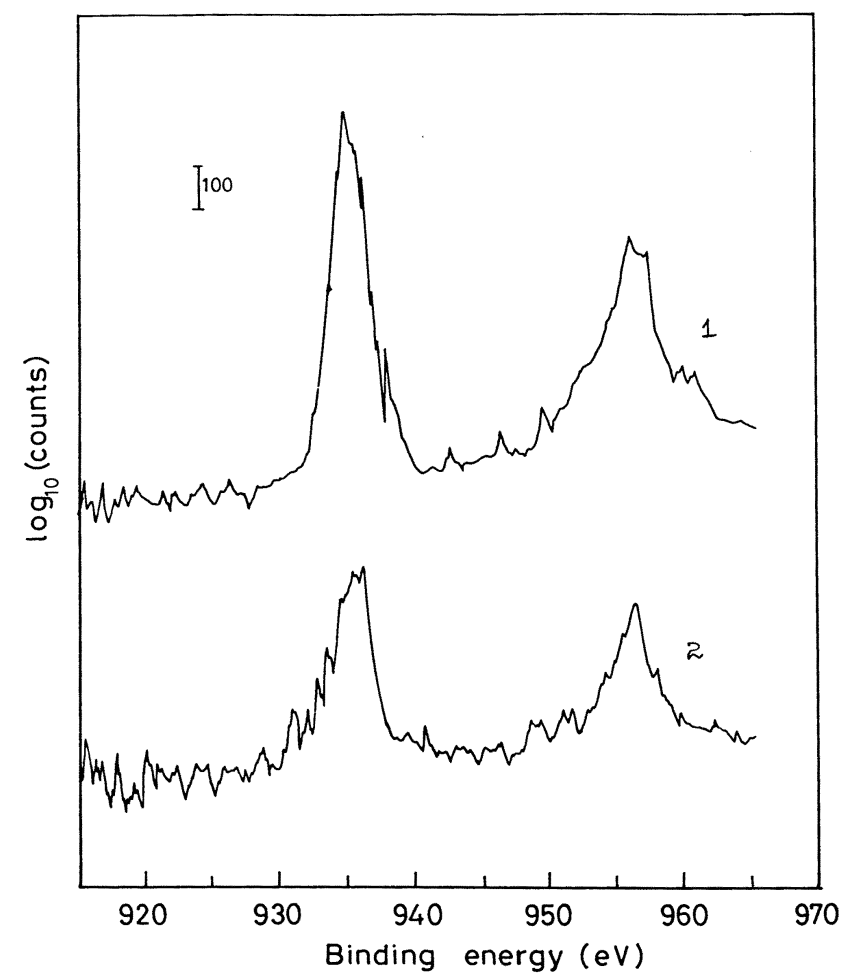

Figure 4. XPS of copper complex (1) after sulphidation and (2) after hydrogenation.

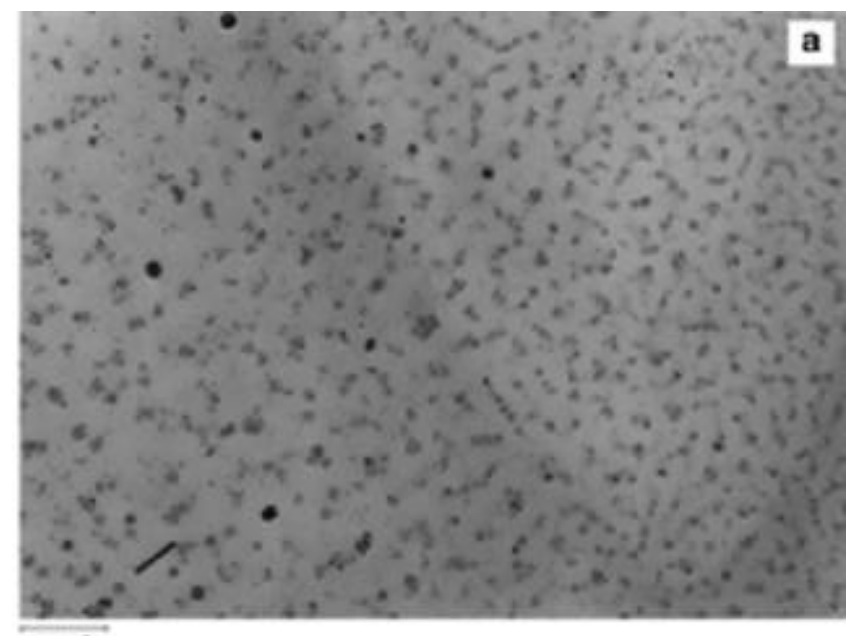

$100 \mathrm{~A}$

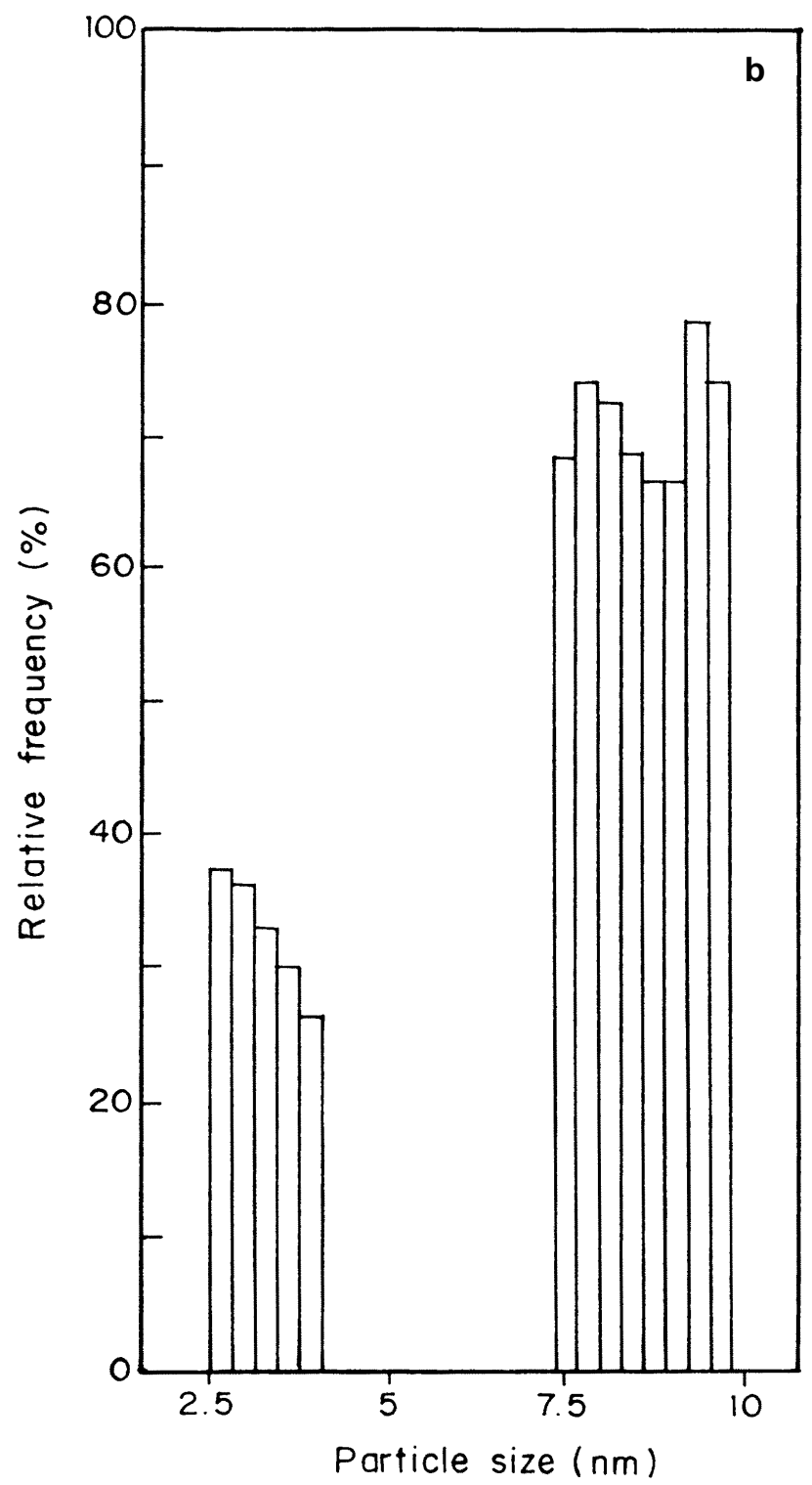

Figure 5. a. Transmission electron micrograph of sample after hydrogenation (scale $b a r=10 \mathrm{~nm}$ ) and b. plot of relative frequency $(\%)$ vs size of particles. 
indicating a strong interaction between $\mathrm{Cu}^{2+}$ and ODSA. During compression-expansion-compression cycles, the curve does not show any hysteresis indicating the stability of the copper complex.

The UV-visible spectra of the copper complex of ODSA and the copper sulphide provide an opportunity to monitor the optical properties. Figure 2 shows the evolution of the absorption spectra of 20-layer (i) copper complex of ODSA, (ii) after sulphidation and (iii) after hydrogenation. The absorption spectra exhibit bands on broad regions between 430 and $600 \mathrm{~nm}$. The sizes estimated from these spectra show a range between 3 and $10 \mathrm{~nm}$. This is usually estimated (Nabok and Richardson $1995)$ from the dependence of the absorption edge on the size according to (1) and (2)

$$
k=A\left(h v-E_{\mathrm{g}}\right)^{1 / 2}
$$

where $A$ is a constant and

$$
h v_{01}=E_{\mathrm{g}}+\left(h^{2} / 8 \pi^{2} \mu a^{2}\right) J_{\mathrm{ln}}^{2}
$$

Here the $J$ values are the roots of the Bessel functions with 1 and $n$ being the angular and spin quantum numbers. The bands are due to the excitation of plasma resonances and are characteristic of the metallic nature of the particles formed. Such well defined plasma resonances are indicative of the metallic behaviour of the clusters formed as has been seen in a host of colloidal elements (Creighton and Eadon 1991).

Figure 3 shows the diffuse reflectance (DIR) spectra of LB films after hydrogenation. For a $10 \mathrm{~nm}$ diameter $\mathrm{Cu}(0)$ particle, the absorption spectra is characterized by a broad absorption with a $570 \mathrm{~nm}$ peak attributed to the plasmon band (Balogh and Tomalia 1998). Generally the size of the metal clusters and the properties of the metal/template interface influence the excitation of surface plasmons. The ligand to metal charge transfer is seen as bands between 350 and $450 \mathrm{~nm}$. The progressive build up in the appearance and intensity of the $570 \mathrm{~nm}$ plasmon peak increases on increasing the size of the clusters. The small peak at about $800 \mathrm{~nm}$ may be due to the metallic particles surrounded by an oxide layer and this agrees with the results of Yanase and Komiyama (1991).

XPS analysis of the LB films of the copper complex after sulphidation and hydrogenation are shown in figure 4 . The elements present in the films are $\mathrm{C}, \mathrm{O}, \mathrm{N}, \mathrm{S}$ and $\mathrm{Cu}$. The spectrum reveals $\mathrm{Cu}\left(2 p_{3 / 2}\right)$ and $\mathrm{Cu}\left(2 p_{1 / 2}\right)$ peaks located at 934.78 and $956.26 \mathrm{eV}$ for the sulphide, and possibly oxides as indicated by $932.4 \mathrm{eV}$ and $952 \mathrm{eV}$ (Yanase and Komiyama 1991) and 936.4 eV and 956.3 eV for the hydrogenated sample, though XPS cannot normally distinguish between $\mathrm{Cu}(0)$ and $\mathrm{Cu}(1)$ (Briggs and Seah 1990). The difference in $\mathrm{Cu}\left(2 p_{1 / 2}\right)$ before and after hydrogenation carried out on the copper sulphide film gives a value of $1.62 \mathrm{eV}$ which corresponds to 2 electron transfer.
Thus it is possible that in figure 4 , curve 2 corresponds to the $\mathrm{Cu}(0)$ state. Figure 5a shows the transmission electron micrograph of a single LB film after hydrogenation with nearly uniform sized copper particles. Occasional clusters can be seen with larger sizes also. Statistical distribution of the particles from this micrograph given in figure $5 b$ show the relative frequency $(\%)$ of the occurrence of various particle sizes.

\section{Conclusions}

In conclusion, the LB film of ODSA can be used as a template to synthesize $\mathrm{Cu}(0)$ particles and it is possible to limit the size of the metallic particles to $3 \sim 10 \mathrm{~nm}$ size. By using mixed monolayers of ODSA with other non reacting matrices like long chain alcohols or amines it should be possible to prevent aggregation and thus to obtain uniformly sized metallic particles. Work is presently underway to investigate such films.

\section{Acknowledgement}

The authors would like to thank the Department of Science and Technology, New Delhi, for a project grant under which this work was carried out.

\section{References}

Creighton Alan J and Eadon Desmond G 1991 J. Chem. Soc. Faraday Trans. 873881

Balogh L and Tomalia D A 1998 J. Am. Chem. Soc. 1207355

Briggs D and Seah M P (eds) 1990 Practical surface analysis (New York: John Wiley \& Sons) 2nd ed. p. 487

Burkett S L and Mann S 1996 J. Chem. Soc. Chem. Commun. 321

Fujihara M and Poosittsak S 1986 J. Electroanal. Chem. 199 481

Haruta M, Koyabashi T, Sano H and Yamada N 1987 Chem. Lett. 405

Hemakanthi G and Dhathathreyan A 1999 Langmuir 153317

Hemakanthi G and Dhathathreyan A 2001 Chem. Phys. Lett. 341407

Jana S and Biswas P K 2000 Bull. Mater. Sci. 23263

Joly S, Kane R, Radzilowski L, Wang T, Wu A, Cohen R E, Thomas E L and Ruber M F 2000 Langmuir 161354

Kotov N A, Dartbello Zaniquelli M E, Meldrum F C and Fendler J H 1993 Langmuir 93710

Kurihara K, Kizling J, Stenius P and Fendler J H 1983 J. Am. Chem. Soc. 952574

Liu M and Cai J 2000 Langmuir 162899

Lisiecki L and Pileni M P 1993 J. Am. Chem. Soc. 1153887

Lisiecki L and Pileni M P 1995 J. Phys. Chem. 995077

Mancin F, Tecilla P and Tonellato U 2000 Langmuir 16227

Meldrum F C, Kotov N A and Fendler J H 1994 Langmuir 10 2035

Nabok A V and Richardson T 1995 Langmuir 103173

Penner Reginald M 2000 Acc. Chem. Res. 3378 
Pileni M P 1997 Langmuir 133266

Preston C K and Moskovita M J 1993 J. Phys. Chem. 978405

Sharma A C and Borovik A S 2000 J. Am. Chem. Soc. 1228946

Tanahasi I and Mitsuyu T 1995 J. Non-Cryst. Solids 18177

Tang R, Jiang C and Tai Z 1997 J. Chem. Soc. Dalton Trans. 4037
Tu W and Liu H 2000 J. Mater. Chem. 102207

Xiong H, Cheng M, Zhou Z, Zhang X and Schen J 1998 Adv. Mater. 10529

Yanase A and Komiyama H 1991 Surf. Sci. 24811

Zhang Y, Li Q, Xie C, Hua B, Chen Y and Tian Z 1996 Thin Solid Films 274150 